\title{
BMJ Open How medical specialists experience the effects of a mindful leadership course on their leadership capabilities: a qualitative interview study in the Netherlands
}

$\overline{\text { Kiki Vreeling, }{ }^{1} \text { Wendy Kersemaekers, }{ }^{1} \text { Linda Cillessen (D) , }{ }^{1,2} \text { Dirk van Dierendonck, }{ }^{3}}$ Anne Speckens ${ }^{1,2}$

To cite: Vreeling $\mathrm{K}$, Kersemaekers W, Cillessen L, et al. How medical specialists experience the effects of a mindful leadership course on their leadership capabilities: a qualitative interview study in the Netherlands. BMJ Open 2019;9:e031643. doi:10.1136/ bmjopen-2019-031643

- Prepublication history and additional material for this paper are available online. To view these files, please visit the journal online (http://dx.doi. org/10.1136/bmjopen-2019031643).

Received 13 May 2019 Revised 14 November 2019 Accepted 18 November 2019

Check for updates

(C) Author(s) (or their employer(s)) 2019. Re-use permitted under CC BY-NC. No commercial re-use. See rights and permissions. Published by BMJ.

${ }^{1}$ Psychiatry, Center for Mindfulness, Radboudumc, Nijmegen, Netherlands ${ }^{2}$ Donders Institute for Brain, Cognition and Behavior,

Radboud Universiteit, Nijmegen, Netherlands

${ }^{3}$ School of Management,

Erasmus Universiteit Rotterdam, Rotterdam, Netherlands

Correspondence to

Ms Linda Cillessen;

linda.cillessen@radboudumc.nl

\section{ABSTRACT}

Objectives Medical leaders are facing leadership challenges that ask for a leadership style that takes care of both themselves and their coworkers. Mindfulness may support this leadership style. We explored how a 'Mindful leadership for medical specialists' course affected medical specialists' leadership.

Design We conducted a qualitative study based on indepth interviews. The grounded theory method was used to analyse the data.

Setting A university medical centre in the Netherlands. Participants Seventeen medical specialists (six male) with an average age of 51 years (ranging from 40 to 66 years).

Interventions The mindful leadership course consisted of 10 -weekly 5 -hour sessions that focused on cultivating mindfulness and compassion. In addition, sessions included didactic and interactional teaching about leadership theories.

Results Four categories emerged from the data: $(A)$ Self - Attitude: psychological attitude towards self, (B) Self - Behaviour: behaviour towards self, (C) Other Attitude: psychological attitude towards others, and (D) Other - Behaviour: behaviour towards others. Themes were defined within these categories: awareness of self, open mind, insight and appreciation of self $(A)$, emotional and cognitive self-regulation, letting go of unhelpful behaviour and developing helpful behaviour (B), differences in attitude to others such as awareness of (impact on) others, keeping an open mind about others, allowing difficult emotions associated with others, appreciating of others $(\mathrm{C})$, and communicating more effectively, providing direction, empowering and caring for others (D).

Conclusions The results help us understand the core elements of mindful leadership, both with respect to one's psychological attitude and behaviour towards oneself and others. More research on mindful leadership and the effects on self and others is needed. Mindful leadership courses could be a valuable part of clinical training and might contribute to more sustainable healthcare organisations.

\section{Strengths and limitations of this study}

- Qualitative interviews with medical specialists with enormous workload.

- Purposive sampling for age, gender, specialty, leadership role and completion of the mindfulness course.

- Interviews were conducted at least 12 months after participants completed the mindfulness course.

- Emerging categories are not always as clearly delineated as the grouping suggests.

- There might be a self-selection bias in our participants, due to the intense programme of the mindfulness course

\section{INTRODUCTION}

Healthcare professionals across America and Europe face pressing challenges. Healthcare institutions must balance limited resources with continuous changes in healthcare systems (eg, insurance), increased production pressure, more administrative tasks and greater amounts of knowledge to digest. ${ }^{12}$ Furthermore, patients have a stronger voice and are more involved in medical decision making. ${ }^{3}$ All these developments have led to high levels of work-related stress among healthcare workers, ${ }^{4-7}$ more dropout than in other sectors ${ }^{8}$ and strong increases in burnout. ${ }^{9} 10$

Combatting work-related stress requires good leadership in healthcare organisations, not only for workers themselves, but also for patients and the organisation as a whole. ${ }^{11}{ }^{12}$ According to WHO, high-quality leadership can help support employees (eg, by providing feedback, being available to help with questions or problems or creating a healthy work environment, ${ }^{12}$ which may ultimately reduce the risk of burnout). ${ }^{13}$ 
Furthermore, variations in the quality of medical leadership can result in compromised patient care, sometimes with catastrophic consequences. ${ }^{14}$ Despite the importance of good leadership, it is difficult to provide a single definition of it because it depends on the context. ${ }^{11}$ In medical settings, healthcare leaders are asked to create an environment that is caring and healthy for patients, staff and the organisation, and to create a strong and engaged culture. ${ }^{12}$ That requires leaders to deploy a range of leadership styles and behaviours that are helpful for themselves as well as their teams and the healthcare environment. $^{15}$

Medical specialists are increasingly in the lead and ultimately responsible for their units' performance. ${ }^{16}{ }^{17}$ However, their medical education rarely equips them to successfully perform leadership tasks in the rapidly changing and demanding healthcare system. $^{2}{ }^{16}$ Therefore, it is increasingly recognised that the current context of healthcare and its requirements ask for education on effective leadership. ${ }^{11}$ It is important that medical specialists receive evidence-based education to equip them with tools for effective leadership. ${ }^{6}$

Mindfulness might be a potent way to support medical specialists in clinical leadership. Mindfulness is defined as intentionally paying attention to the present moment in a non-judgemental way ${ }^{18}$ and it helps practitioners uncover habitual behavioural patterns and their attitudes towards themselves, others and experiences. A recent metaanalysis on determinants of effective leadership training found that programmes focused on self-awareness and intrapersonal content, which are inherent to mindfulness, are among the most effective in terms of results. ${ }^{19}$ However, these interventions are also least studied, ${ }^{19}$ and therefore a mindful leadership course is the focus of the current study.

Research has found that mindfulness may improve leadership via two pathways. First, mindfulness has been demonstrated to reduce perceived stress, depression and anxiety, and to improve well-being and quality of life in healthy individuals. ${ }^{20}$ Furthermore, there is some evidence that mindfulness may help medical specialists in their professional settings. ${ }^{21-23}$ Given that medical specialists are experiencing burnout symptoms at epidemic levels, ${ }^{9}$ addressing their personal health is important. When medical specialists are less absorbed by their own complaints and symptoms, their leadership skills may improve automatically.

Second, mindfulness may directly target leadership skills. Cross-sectional research among a diverse sample with leaders from different work fields found positive associations between leaders' trait mindfulness and employees' well-being, job performance and satisfaction. ${ }^{24}$ Employees with a mindful leader feel they are treated with greater respect and experience less stress. ${ }^{25}$ Finally, research has shown that mindfulness improves various areas relevant to leadership, ${ }^{26}$ such as self-regulation (including attention regulation, emotion regulation and self-awareness). ${ }^{27}$ This may lead to improved relationships with employees, ${ }^{24}{ }^{28}$ improved communication ${ }^{29} 30$ and increased compassion and empathy. ${ }^{31-33}$

Most empirical studies operationalise mindfulness within the leadership context by asking leaders to fill out a mindfulness measure, which neglects its integration and explication in their leadership behaviour and attitudes.e.g. ${ }^{34}{ }^{35}$ To advance the field, this qualitative study addresses the perceived impact of mindfulness training on leadership among medical specialists. The Radboud Centre for Mindfulness developed a course, 'Mindful leadership for medical specialists', which addressed mindfulness and leadership centring on mindfulness leadership components added as a bridge to daily practice. In addition to studying the perceived effects of the course, we used our data to build a theoretical framework for the concept of mindful leadership.

\section{METHODS}

We conducted this qualitative study among a subsample of participants in a non-randomised waitlist-controlled prepost study on the effects of a mindful leadership course on medical specialists' burnout symptoms, psychological well-being and leadership skills. ${ }^{36}$ According to Dutch law, the non-medical and non-experimental nature of the study, combined with the minimal risks and burdens for participants, meant that this study did not require review by the Medical Ethical Committee Arnhem/Nijmegen, the Netherlands. All study participants provided informed consent. We followed the COREQ ${ }^{37}$ and $\mathrm{SRQR}^{38}$ checklists for reporting qualitative research.

\section{Participants}

We recruited medical specialists from various hospitals in the eastern part of the Netherlands for the parent study on the mindful leadership course. Participation in the course was voluntary. In total, five cohorts attended the mindful leadership course, totalling 52 medical specialists overall. Of those 52 medical specialists, we emailed 25 to ask for their participation in this study. Seventeen of the 25 invitees agreed to participate.

We used purposive sampling to equally represent characteristics such as age, gender, specialty, leadership role and completion of the course. All 17 participants completed the interviews. Six $(35 \%)$ of them were men and their average age was 51 years (varying from 40 to 66year). Eight (47\%) participants had an internal specialty, five (29\%) had a supportive specialty (ie, anaesthesiology, pathology, medical microbiology, radiology, or radiotherapy) and four (24\%) had a surgical specialty (table 1). Participants held various leadership roles: managing departments or teams, role-modelling and teaching medical residents and students.

\section{Course description}

The 'Mindful leadership for medical specialists' course consisted of 10-weekly 5-hour sessions in the afternoon and evening with a dinner break in between. The group 


\begin{tabular}{|c|c|c|}
\hline Identification number & Gender & Specialty (category) \\
\hline 1 & Male & Supportive \\
\hline 2 & Male & Internal \\
\hline 3 & Female & Internal \\
\hline 4 & Female & Supportive \\
\hline 5 & Male & Surgical \\
\hline 6 & Female & Supportive \\
\hline 7 & Male & Internal \\
\hline 8 & Female & Internal \\
\hline 9 & Female & Supportive \\
\hline 10 & Female & Surgical \\
\hline 11 & Male & Surgical \\
\hline 12 & Female & Surgical \\
\hline 13 & Female & Internal \\
\hline 14 & Male & Internal \\
\hline 15 & Female & Internal \\
\hline 16 & Female & Supportive \\
\hline 17 & Female & Internal \\
\hline
\end{tabular}

size varied from eight to sixteen participants. The course included the original Mindfulness-Based Stress Reduction (MBSR) programme developed by Jon Kabat-Zinn. ${ }^{18}$ The original 8-week programme consists of weekly group sessions that include mindfulness meditation (eg, body scan, sitting meditation, gentle movement exercises), psychoeducation about stress and group discussions. Home meditation practice ( $45 \mathrm{~min}$ per day) is an important aspect of the programme. Furthermore, one session consisted of a silent retreat. Participants learnt to focus their attention on the present moment and observe their own thoughts, feelings and behaviour in a kind and non-judgemental way rather than identifying with them (meta-awareness). They were encouraged to become aware of their own automatic behavioural patterns and consider replacing them with more helpful behaviour. In addition to the MBSR, the course consisted of experiential teaching sessions on cognitive behavioural therapy, compassion ${ }^{39} 40$ and three frameworks relevant to becoming a better leader.

The three leadership frameworks presented were Covey's habits for leadership success ${ }^{41}$ Hersey's situational leadership ${ }^{42}$ and Scharmer's Theory U. ${ }^{43}$ Covey presents the seven habits of highly effective people, progressing from independence to interdependence. ${ }^{41}$ Hersey describes effective leaders as those who adapt their leadership style to the performance readiness (ability and willingness) of the individual or group they are attempting to lead. ${ }^{42}$ Scharmer's Theory U describes a process of letting-go (of our old ego and self) and letting-come (our highest future possibility: our self) in which the bottom of the U is 'presencing', where these two selves meet and begin to listen to and resonate with each other. ${ }^{43}$ These theories were chosen because of their relatedness to mindfulness. Each introduces overlapping themes of becoming more aware of self and others, being more in the present (instead of in the past or future), being more in the being-mode (vs the doing-mode), practising more conscious (instead of automatic) decision making, listening more carefully and becoming more sensitive to employees' needs. After being trained in each of these frameworks, participants learnt and planned how to apply their new knowledge to their daily leadership activities in the weeks between sessions.

\section{Procedure}

Two of us (WK and KV) interviewed the medical specialists 12 to 18 months after their participation in the mindful leadership course (which occurred between September 2014 and June 2016). We used a semistructured style for the interviews. The topic guide (see online supplementary material 1) focused on the perceived impact of the course with follow-up questions about impacts on their leadership skills and the facilitators and barriers to participating in the course. If not mentioned by the interviewees, the interviewers asked specific questions related to planning and organising work, managing people and developing vision and strategies. The interviewers asked participants whether they attributed the perceived impacts on their leadership to the course. Fifteen of the interviews were conducted in person, the other two were done by telephone. All interviews were conducted in Dutch and recorded. The average interview time was up to an hour. Interviews took place at a location chosen by the participant, which was usually their workplace.

\section{Data analysis}

All interviews were recorded and transcribed verbatim. Data were anonymised and unique research codes were added to the interviews and transcripts. We analysed the data using Atlas.TI7, ${ }^{44}$ a software package for qualitative analysis.

We used the grounded theory approach to analyse the data. ${ }^{45}$ We chose that approach so we could generate a theorical framework of the perceived impact of mindful leadership in practice. Furthermore, the grounded theory approach is an excellent tool for analysing a social phenomenon like mindful leadership, which is an under-researched area. ${ }^{45}$ It is a data-driven method in which the data forms the only input for the theory, which reduces bias from researchers' perspectives and previous theorising about mindful leadership. ${ }^{47}$ However, this approach is vulnerable to relativism (ie, researcher interpretation) ${ }^{47}$ which stresses the importance of a diverse research group.

The grounded theory approach uses data coding (labelling and categorising). Codes that are derived from the data are used to create categories in a theoretical framework with three phases of coding, namely open coding, axial coding and selective coding. ${ }^{48}$ Data analysis begins when the first interview is conducted, and 
continuous adaptations in the codes and topic guide are an integral part of this method. Three researchers (HvR, WK, KV) coded independently to minimise subjectivity. After every two or three interviews, they compared and discussed codes and reached consensus. In each meeting, the researchers updated the coding scheme, added new codes and combined similar codes. In this phase, open coding was mostly used, which consists of reading and re-reading the interviews and developing a coding three.

After eight interviews, a different group of researchers (AS, WK, KV) began dividing the codes into themes with axial coding, in which a list of categories and (sub) themes is made from the list of codes. Based on discussion in research team, the topic guide was adjusted for subsequent interviews to collect more detailed information about leadership roles. After 14 interviews, no new codes were emerging from the data. This indicated that saturation had been reached, as all new data fitted into the existing codes. ${ }^{45}$ We still conducted and coded three more planned interviews to confirm this.

After the 17 interviews were transcribed and coded, two researchers (WK and KV) grouped the codes again with axial coding. In two group discussions, the research team (except LC) grouped the codes into themes and categories derived from the themes, to find the core categories (selective coding). We discussed the themes and categories until we reached consensus. The categories originated naturally from the data and showed familiarity with mindfulness theory and practice. During and after the process of defining themes, we continuously checked with the original data to make sure themes fitted. Finally, we selected illustrative quotes for each of the selected themes and translated them into English. Translations were checked by a native English professional translator.

\section{Credibility of the data}

The research group had different backgrounds and knowledge, which facilitated a broad view due to different perspectives. The group consisted of a professor in psychiatry/mindfulness trainer (AS), a business researcher/ professor in leadership (DvD), a senior researcher/mindfulness trainer (WK), a PhD student/psychologist (LC) and a business consultant/mindfulness trainer (KV).

The interviewers (WK and KV) did not have any relationship with the participants prior to the study, which increases credibility by reducing the chance of socially desirable responses. WK and KV expected the mindfulness training to have positive effects on leadership skills. Participants were given the rationale for the study (so they could provide informed consent), but they did not know the interviewers' personal goals, which may also reduce socially desirable responses. Only the interviewer and participant were present for each interview. The participants did not receive interview transcripts, but transcripts were carefully created and checked with the audio files of the interviews. Participants did not provide feedback on the study findings.

\section{Patient and public involvement}

There were no patients involved in this study, which focused on medical specialists. Results will be communicated to the participating medical specialists.

\section{RESULTS}

One participant (no. 11) said that the intervention did not have any perceptible effects on his leadership or personal life. However, the other participants did report effects, of which results are described below.

Four categories originated naturally from the data and resulted in a model with two dimensions: attitude versus

\section{Self}

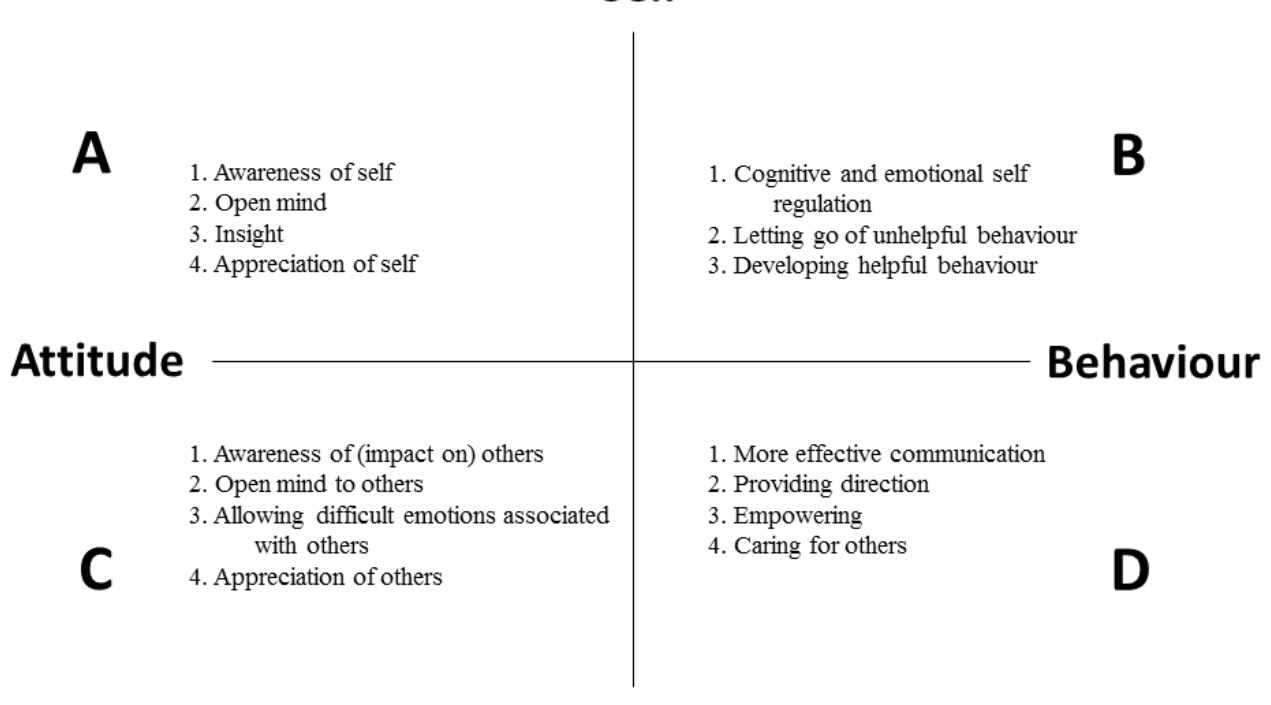

\section{Others}

Figure 1 Two-dimensional model of mindful leadership. 
behaviour and self versus others (see figure 1). Through an iterative process, we reduced the 200 codes to 15 themes describing a process. These themes describe the four categories with the underlying two dimensions. They are described below. Quotes for each theme can be found in table 2.

The core dimensions of our model are 'Self' versus 'Other' and 'Attitude' versus 'Behaviour'. 'Self' in our model refers to the attitude and behaviour towards oneself. 'Other' refers to the attitude and behaviour towards others. The Attitude versus Behaviour dimension aligns with the being versus doing dimension that can be found in mindfulness literature. ${ }^{49}$ One has a tendency to constantly do as a habitual behaviour on automatic pilot as opposed to simply being and experiencing the moment. In a mindfulness course, participants experience the difference between 'doing' and 'being'.

In our model 'Attitude' describes different attitudes in being towards self and others. 'Behaviour' describes intentional behaviour: a chosen action, internal or external, done deliberately and with awareness. Combining these two dimensions creates the following four categories:

A. Self - Attitude: Psychological attitude towards self.

B. Self - Behaviour: Behaviour towards self.

C. Other - Attitude: Psychological attitude towards others.

D. Other - Behaviour: Behaviour towards others.

Within these categories, we identified different themes (figure 1).

The responses from the participants described a process from attitude to behaviour. Categories were often interrelated and could strengthen each other. This can be seen in the quotes (table 2), which often contain themes from different categories.

\section{Self - Attitude}

The first category in which the participants mentioned an impact of the training is their psychological attitude towards themselves as leaders. It is a development in which awareness and an open mind lead to insight and an appreciation of self. We gathered four themes.

\section{Awareness of self}

Participants described an awareness of their internal processes like their emotions, the coming and fading away of emotions like stress or tension, physical reactions to their emotions and their own behaviour in situations.

\section{Open mind}

Participants described how mindfulness helped them see the bigger picture and notice what is there. They reported an ability to observe from a distance, take a wider perspective and look at what is happening. They described having a fresh view and being contemplative.

\section{Insight}

Participants mentioned having more insight into what triggers them to exhibit certain behaviour or make a decision. They reported enhanced self-reflection.
Appreciation of self

Participants described being more accepting of who they are and noticed more confidence in their own capacities. They reported being more at ease, less self-critical and more relaxed. They described realising and accepting that they are good at what they do. Two participants described how they now value their own opinions on matters and are aware of what they find important in their lives. Furthermore, they described being or feeling more confident.

\section{Self - Behaviour}

The second category involves behaviour of leaders directed towards themselves in their role as a leader.

\section{Cognitive and emotional self-regulation}

Participants indicated regulating their emotions by recognising their thoughts and behaviour. They described how they regulate their thoughts and emotions by intentionally seeing thoughts as just thoughts, taking time for their emotions, keeping a distance from them, exploring their behaviour and using their breath to calm down.

\section{Letting go of unhelpful behaviours}

Participants described letting go of unhelpful behaviour: consciously 'not-doing' such as not or not continuously checking emails, not uncritically accepting requests from colleagues, not doing things that are not priorities for themselves, not getting involved, not multitasking or not reacting to a situation. They described choosing to step out of the habitual act of doing and deliberately refraining from it.

\section{Developing new helpful behaviours}

Participants described acknowledging and allowing their needs, standing up for themselves and acting accordingly. For example, they described expressing their opinion, blocking time in their agenda for themselves, planning and taking a rest and making choices that suit them.

\section{Other - Attitude}

The third category is the psychological attitude towards others. It consists of four subcategories:

Being aware of one's (impact on) others

Participants described being more aware of others. They mentioned paying more attention to others and being really present with them. They also reported being more aware of the positive or negative impact of their communication (verbal or nonverbal) or their behaviour on others. For example, participants noticed the impact of an inconsiderate remark or tone of voice.

\section{Keeping an open mind towards others}

Participants mentioned not having a fixed mindset and described a more open, accepting and exploratory attitude towards others. They reported being less judgemental, omitting judgements in situations or reconsidering judgements when they noticed they had them. 
Table 2 Categories, themes and illustrative quotes derived from the qualitative interviews

\section{Category and Themes Illustrative quotes}

Self - Attitude 1. Awareness of self

No. 3 - "...what I then notice is that I start breathing faster, I also start talking louder, start interrupting others..."

2. Open mind

No. 17 - "That you're not so caught up in yourself or the everyday hustle. You can view things from a distance and that gives you a broader perspective."

3. Insight

No. 14 - "...you can (...) definitely also see that as an outcome of the course, that I think 'well you need to watch out now, look at what's happening, what is it that triggers you?'."

4. Appreciation of self

No. 13 - "That as a tutor too I stick to my own qualities more, and am more confident about those, and can more easily say 'I simply want to know this or that' and 'that's my style of training.' And that's made me more confident."

Self - Behaviour

1. Cognitive and emotional regulation

No. 14 - “...to then focus on your breathing, take deep breaths, and, pull yourself back together in a physical sense..."

2. Letting go of unhelpful behaviour

No. 12 - "We've talked about that, about how much we let our phones and email run our lives. And us constantly checking. You don't need to at all, of course. People can easily wait a day. They don't need an answer within five minutes."

3. Developing new helpful behaviours

No. 9 - "(...) dealing with pressure in a different way (...), taking a moment for myself more often, taking a break when it's break time and going outside for a walk and thinking 'bye guys, I'm just popping out to get some fresh air'. And taking more moments in between just to rest for a moment."

Other - Attitude

1. Being aware of one's impact on others

2. Keeping an open mind towards others

3. Allowing difficult emotions associated with others

No. 9 - "In conversations with others too (....). I think you start looking at it from a different perspective, you become more empathetic I think and more sensitive to 'how does the other person feel about what l'm saying?' and 'how would I feel about it?'."

No. 14 - "Especially by separating the content from the person talking, and so listening to the story from a very neutral perspective. What is the message? Where is the conflict? Depending on what presents itself, and then keeping the judgement as focused on the content as possible, as factual as possible and not letting it be coloured by the way the story is told or any undertones you might be hearing." No. 3 - "I judge less. And I'm actually very happy with that. Especially if you then look back at yourself, that I thought 'you know. Everyone is different of course.' And I often had an opinion about that or was quick to judge.'

No. 8 - "We had just come out of a very hectic period, and (...) a sensitive and serious conflict (...) and as the manager I was right in the middle of that, and it wasn't easily resolved (...) A great deal of investment was needed for many of the relationships that had been seriously damaged, so that was quite a challenge too and at times when it didn't go as quickly as I'd hoped, I simply needed to grin and bear it."

4. Appreciating others

No. 16 -"He's a bit neurotic and very particular and deals with people in a very different way that I do. And very dedicated to his work, but I put a kind of negative spin on that (...) Whereas now (...) I look at things differently (...) when I look at him now, I see a man who has truly dedicated his life to his work."

Other - Behaviour

1. Communicating more effectively

No. 14 - “...then it's listening, isn't it, really just listening and nothing else, just listening." No. 16 - "... being more open towards that and asking more questions. Asking 'why', 'can you pinpoint why exactly you aren't doing well?' 'Can you articulate what you want, what you need?' That I guess, asking more questions and more, well that means not drawing your own conclusions, but getting more to the bottom of things." No. 3 - "(...) then I just show there's nothing wrong with admitting you don't know something. Or that you'd like to use someone else's expertise."

2. Providing direction
No. 10 - "I think now that l've given myself more direction and I can more clearly outline the direction for the people I manage." 
Table 2 Continued

\begin{tabular}{|c|c|}
\hline Category and Themes & Illustrative quotes \\
\hline 3. Empowering & $\begin{array}{l}\text { No. } 5 \text { - "But experience by now has taught me that the less I interfere (...) the more people } \\
\text { start to develop talents (...) That helps people develop and the product may actually be } \\
\text { better, especially for those people themselves, because there's a greater sense of them } \\
\text { having done it themselves. So taking more distance, not interfering too much." No. } 3 \\
\text {-"Putting someone down, because that would then feed my ego. That is not at all beneficial } \\
\text { to what we need to do, to delivering good patient care. (...) I think well, then I'll take myself } \\
\text { as an example, and they picked up on that, that I said something along the lines of 'I don't } \\
\text { know this', 'Can you contribute any thoughts on this?' Or 'I did it for this or that reason, but } \\
\text { maybe you have other ideas, or maybe I overlooked something'?" }\end{array}$ \\
\hline 4. Caring for others & $\begin{array}{l}\text { No. } 9 \text { - "I also noticed with the colleague who's had a burnout, that I was the first to notice } \\
\text { that he was burning out and that it started being an issue and that I see it in other colleagues } \\
\text { (...) You're much more aware, not only of yourself, but also of other people around you." No. } \\
16 \text { - "And then I try to put them at ease a bit that way, by saying 'You can't do everything at } \\
\text { once, so try to take it one step at a time.' You hope it helps someone a bit." }\end{array}$ \\
\hline
\end{tabular}

Focusing on facts and content rather than the emotions associated with a person helped them separate emotions from facts.

\section{Allowing difficult emotions associated with others}

This involves being open to difficult things. Participants mentioned how they allowed and tolerated difficult situations and behaviour. They mentioned being patient with others who exhibited difficult behaviour.

\section{Appreciating others}

Apart from having a nonjudgemental attitude towards others, participants described how they now see others' value more. They realise that people are different and do not necessarily have the same ideas and ambitions. They have a greater understanding of other people's situations. One participant described seeing people as more equal.

\section{Other - Behaviour}

The fourth category involves changes in observable behaviour towards others. It includes four subcategories:

\section{Communicating more effectively}

As part of communicating openly, the participants mentioned listening, asking for clarification and connecting with others by sharing expectations, the experienced workload or their own vulnerability. This theme was overwhelmingly present in the data.

Most participants mentioned listening with more attention as a direct effect of the training. They described an ability to let go of control during communication and really listen to the other person with attention and focus. They mentioned refraining from interrupting or finishing other people's sentences. They mentioned having more in-depth discussions and more effective conversations. Participants reported feeling confident in their ability to capture essential information, understand key points and understand another person.

Furthermore, participants not only reported listening more, but also asking more questions to get clarification. They asked questions like "What do you mean by that?" or "Can you tell me what you need?" They also invited so-called 'difficult people' to join in conversations and engage with decisions.

Participants mentioned connecting and aligning more with their colleagues. They reported working together and sharing their experiences, such as workload, expectations towards one another and their own vulnerability.

\section{Providing direction}

Participants described an ability to express more clearly how they see things, what they want and how they want it. They described expressing a vision towards others and acting on it. They mentioned formulating their ideas more clearly towards others.

\section{Empowering}

Participants described how they consciously refrained from responding to emails to tell others what to do and developed behaviour that facilitated others. They described how they now give their employees more responsibility and trust that what they do is right. That allows employees to develop, and the participants did not intervene with their learning process. Instead of telling employees what to do, the participants coached them and discussed their personal development with them.

\section{Caring for others}

Participants described a certain care for their colleagues. They mentioned actions like devoting more time to their colleagues, paying more attention to their well-being and keeping in contact with them when they were on sick leave. One participant described how he fired someone with compassion.

Participants also mentioned encouraging others to take care of themselves. They described advising others to practice mindfulness or transmitting to others what they had learnt in the course (eg, being less judgemental and kinder towards yourself). They mentioned being milder towards others and encouraging others to do so. 
Apart from effects on their leadership, participants also mentioned results of the process of practising mindfulness in their leadership. The answers can be divided in two subcategories:

1. Greater satisfaction in work

They described having a more pleasant and productive contact with their colleagues and the patients.

\section{Efficiency}

Participants described that the effort they put in the organisation had a bigger return on investment and that they received more appreciation from their employees.

\section{DISCUSSION}

This qualitative study addressed the perceived impact of mindfulness training on leadership by medical specialists. In addition to the dimension of self versus other, we identified a dimension of attitude versus behaviour, which can also be described as 'being' versus 'doing'. ${ }^{49}$ The psychological attitude towards oneself was characterised by more awareness, an open mind, insight and an appreciation of self. In terms of behaviour towards oneself, participants reported better emotional and cognitive self-regulation, which involved letting go of unhelpful behaviours and developing new helpful behaviours. The change of attitude towards others was characterised by having more awareness of others and one's own impact on others, keeping an open mind towards others, allowing difficult emotions associated with others and appreciating others. Changes in behaviours towards others consisted of communicating more effectively, providing directions, empowering and caring for others.

The data also showed that the four categories are interrelated. For example, when people appreciate themselves more, this can result in better self-care (B), a more appreciative attitude towards others $(\mathrm{C})$ and more caring for others (D). Insight seems to precede behavioural changes, although not all insights lead to behavioural change. It is possible that resources for behavioural change (eg, time and energy) are not (yet) available but will be in future. Therefore, some effects of the intervention may become visible long after the intervention has ended.

\section{Contribution to previous research}

Our model is in line with findings from previous research. Another study that involved healthcare workers after a mindfulness intervention described an increased open mind, awareness of self, insight, self-acceptance, letting go of unhelpful behaviour and developing helpful behaviour. ${ }^{32}$ It also reported perceived effects in the interpersonal domain, like listening, empathy and acceptance of others. ${ }^{32}$ Irving et al described an influence of mindfulness on leaders' emotional regulation and self-awareness. ${ }^{50}$

Furthermore, previous research showed that leaders' mindfulness is related to employees' well-being. ${ }^{24}$ Our study revealed some potential pathways to explain this relationship. Leaders said that awareness of their leadership style helps them communicate more effectively and provide clearer instructions. Furthermore, they are more aware of their employees' mental and physical states, which helps leaders empower and care for them; this is in line with a previous qualitative study on mindfulness and leadership. ${ }^{51}$ However, other pathways may exist, especially those that appear unconsciously and are difficult to reflect on in interviews. Interviews with employees or observation studies may help to elucidate these pathways. Furthermore, personal relationships may also improve, although that is beyond the scope of this study. ${ }^{52}$ These improved personal relationships may also have a positive effect on performance at work and as a leader.

Good $e t a l^{28}$ suggested that mindfulness may enhance the effects of a leadership course. Our study, although qualitative, found that medical specialists report beneficial outcomes from a combined course, which provides some support for that idea. Rigorous randomised controlled trials of leadership courses with and without mindfulness would be necessary to truly test this idea. However, previous research did find that a mindfulness communication course had beneficial effects on conversations with patients, ${ }^{30}$ while another study of a mindful leadership course reported benefits to communication with colleagues and employees. ${ }^{33}$

One participant in our study reported that the course had no perceived benefits on their leadership skills or personal life. Mindfulness-based interventions like the leadership course may not be equally beneficial for all participants. for example, ${ }^{53}$ Therefore, it is important that future research address the question of who is likely to benefit and who is not, and raise awareness of alternative leadership courses that might be a better match for certain medical specialists.

\section{Relation to different leadership styles}

Studying the perceived effects of a mindful leadership course gave us insight into the nature of mindful leadership. Our model builds on and extends current theorising on positive leadership grounded in ethical and moral values. Some themes correspond with aspects of other leadership styles, most notably authentic leadership and servant leadership. Authentic leadership focuses on greater self-awareness, an internalised moral perspective, balanced information processing and transparency in behaviour towards others. ${ }^{54}$ In our results, we also see the aspect of self-awareness that is also an element of authentic leadership has and, like authentic leadership, mindful leadership involves behaviour that promotes greater psychological capacity through cognitive and emotional self-regulation. A unique quality of mindful leadership is the more explicit incorporation of a behavioural component with a broader behavioural spectrum, going beyond transparent authentic behaviour and the strong attitudinal focus of authentic leadership.

We also see a link with servant leadership, which has been described as having six characteristics: empowering 
and developing people, humility, authenticity, interpersonal acceptance, providing direction and stewardship. ${ }^{55}$ The characteristics of empowerment and interpersonal acceptance overlap with mindful leadership. Empowerment describes a leader's focus on employees' autonomy, enhancing their personal growth and having a general coaching attitude. All these elements are part of mindful leadership to greater or lesser degrees. We also see a link with the interpersonal acceptance dimension of servant leadership: the themes 'awareness of others', 'open mind to others' and 'appreciating others' from our results dovetail with this characteristic of servant leadership. Mindful leadership differs in that the focus is both on self and others. Servant leadership is grounded in serving others, the six characteristics are all defined in terms of the relation between leader and follower. Mindful leadership describes more explicitly and in deeper detail the intrapersonal aspect of being a leader through different helpful attitudes and behaviour. Thus, mindful leadership offers components not present in authentic or servant leadership. Although our data are qualitative and require further quantitative research, they suggest that mindful leadership adds components that are relevant to leadership in a medical setting.

\section{Strengths and limitations}

One strength of this research is that we were in the unique position to conduct interviews about the application of mindful leadership in real life with a group of participants who have enormous workloads. These interviews and real-life examples gave us the insights we needed. We applied purposive sampling that considered age, gender, specialty, leadership role and completion of the course, to make sure a large variety of perspectives was included, which is a strength in qualitative research. All the interviews were conducted by researchers who were not the teachers, which made the responses less prone to subjectivity. The research group that analysed the data consisted of researchers with a variety of expertise, to avoid bias from particular perspectives. A final strength is that the interviews were conducted no less than 12 months after the course ended, which made it possible to say something about how the lessons from the course were integrated into daily work practice.

Despite its strengths, this research also has some limitations. First, categorising was helpful when analysing the results, but it sometimes felt forced and artificial. In reality, the distinction between the different categories were not always very sharp. For example, being aware of your judgement about a colleague was categorised as an awareness related to others. But a case could also be made for labelling it as awareness of self. Clearly the categories influence each other, and the reality is not static. The same applies for the themes within categories. Second, our mindful leadership course was an intense programme. Therefore, it is possible that self-selection for participation created a bias in the participants, which may compromise the study's generalisability. Finally, we only focused on the perspective of the medical specialists themselves, which can be seen as limitation. The perspective of their employees could also be informative, which is an interesting avenue for future research. Despite these limitations, we feel that this study adds to the research on mindful leadership in general, and leadership among medical specialists in particular.

\section{Implications}

Our results reflect changes in psychological attitudes and observable behaviours and are a first attempt to define mindful leadership and its components. Furthermore, they suggest that a mindful leadership course may be a valuable training option for medical specialists. More research on mindful leadership and the effects on self and others is needed. Future research may address the effects of the course from the perspective of employees, and randomised controlled trials with large samples are needed to address effectiveness. Furthermore, it may be valuable to study beforehand who will benefit from the course.

Acknowledgements The authors wish to thank Dr Hiske van Ravensteijn for her contribution to the coding of the data.

Contributors KV contributed to the conception and design, acquiring data, analysing and interpreting data, drafting and revising the article, and approving the final version. WK contributed to the conception and design, acquiring data, analysing and interpreting data, drafting and revising the article, and approving the final version. LC contributed to drafting and revising the article and approving and submitting the final version. DvD contributed to analysing and interpreting data, drafting and revising the article, and approving the final version. AS contributed to the conception and design, acquiring data, analysing and interpreting data, drafting and revising the article, and approving the final version.

Funding The authors have not declared a specific grant for this research from any funding agency in the public, commercial or not-for-profit sectors.

Competing interests AS is the director of the Radboudumc Center for Mindfulness and WK, LC and KV were employed by the Radboudumc Center for Mindfulness at the time of this study.

\section{Patient consent for publication Not required.}

Ethics approval According to Dutch law, the non-medical and non-experimental nature of the study, combined with the minimal risks and burdens for participants, meant that this study did not require review by the Medical Ethical Committee Arnhem/Nijmegen, the Netherlands. The principles of the Declaration of Helsinki were followed wherever applicable. In addition, participants agreed to participate by signing an informed consent. Data were treated confidentially and according to the Dutch 'Protection of personal data' law.

Provenance and peer review Not commissioned; externally peer reviewed.

Data availability statement No data are available.

Open access This is an open access article distributed in accordance with the Creative Commons Attribution Non Commercial (CC BY-NC 4.0) license, which permits others to distribute, remix, adapt, build upon this work non-commercially, and license their derivative works on different terms, provided the original work is properly cited, appropriate credit is given, any changes made indicated, and the use is non-commercial. See: http://creativecommons.org/licenses/by-nc/4.0/.

\section{ORCID iD}

Linda Cillessen http://orcid.org/0000-0003-2030-8646

\section{REFERENCES}

1 Koplan JP, Fleming DW. Current and future public health challenges. JAMA 2000;284:1696-8.

2 Kumar S. Burnout and doctors: prevalence, prevention and intervention. 37. Healthcare: Multidisciplinary Digital Publishing Institute, 2016. 
3 Visser MR, Smets EM, Oort FJ, et al. Stress, satisfaction and burnout among Dutch medical specialists. Cmaj 2003;168:271-5.

4 Epstein R. Attending: medicine, mindfulness, and humanity: Simon and Schuster 2018.

5 Blau R, Bolus S, Carolan T, et al. The experience of providing physical therapy in a changing health care environment. Phys Ther 2002:82:648-57.

6 West M, Dawson J, Admasachew L, et al. Nhs staff management and health service quality. London: Department of Health, 2011.

7 Shanafelt TD, Hasan O, Dyrbye LN, et al. Changes in burnout and satisfaction with work-life balance in physicians and the general us working population between 2011 and 2014. Mayo Clin Proc 2015;90:1600-13.

8 Shanafelt TD, Boone S, Tan L, et al. Burnout and satisfaction with work-life balance among US physicians relative to the general US population. Arch Intern Med 2012;172:1377-85.

9 Anderson P. Medical resident burnout reaches epidemic levels. Caring for residents 2017;

10 Prins JT, Hoekstra-Weebers JEHM, Gazendam-Donofrio SM, et al. Burnout and engagement among resident doctors in the Netherlands: a national study. Med Educ 2010;44:236-47.

11 Sklar DP. Leadership in academic medicine: purpose, people, and programs. Academic Medicine 2018:93:145-8.

12 Wiskow C, Albreht T, De Pietro C. How to create an attractive and supportive working environment for health professionals. Geneva: World Health Organization, 2010.

13 Wallace JE, Lemaire JB, Ghali WA. Physician wellness: a missing quality indicator. The Lancet 2009;374:1714-21.

14 Warren OJ, Carnall R. Medical leadership: why it's important, what is required, and how we develop it. Postgrad Med J 2011;87:27-32.

15 Ham C. Leadership and engagement for improvement in the NHS: together we can. Report from the King's Fund on Leadership Review, 2012.

16 Malik RF, Hilders CGJM, Scheele F. Do 'physicians in the lead' support a holistic healthcare delivery approach? A qualitative analysis of stakeholders' perspectives. BMJ Open 2018;8:e020739.

17 Denis J-L, van Gestel N. Leadership and innovation in healthcare governance. The Palgrave international handbook of healthcare policy and governance: Springer, 2015: 425-40.

18 Kabat-Zinn J, Hanh TN. Full catastrophe living: using the wisdom of your body and mind to face stress, pain, and illness: delta, 2009.

19 Lacerenza CN, Reyes DL, Marlow SL, et al. Leadership training design, delivery, and implementation: a meta-analysis. J Appl Psychol 2017;102:1686-718.

20 Khoury B, Sharma M, Rush SE, et al. Mindfulness-based stress reduction for healthy individuals: a meta-analysis. J Psychosom Res 2015;78:519-28.

21 Dobkin PL, Bernardi NF, Bagnis Cl. Enhancing clinicians' well-being and patient-centered care through mindfulness. J Contin Educ Health Prof 2016;36:11-16.

22 Verweij $\mathrm{H}$, van Ravesteijn $\mathrm{H}$, van Hooff MLM, et al. MindfulnessBased stress reduction for residents: a randomized controlled trial. $J$ Gen Intern Med 2018;33:429-36.

23 Verweij $\mathrm{H}$, van Ravesteijn $\mathrm{H}$, van Hooff MLM, et al. Does mindfulness training enhance the professional development of residents? A qualitative study. Academic Medicine 2018;93:1335-40.

24 Reb J, Narayanan J, Chaturvedi S. Leading mindfully: two studies on the influence of supervisor trait mindfulness on employee well-being and performance. Mindfulness 2014;5:36-45.

25 Reb J, Chaturvedi S, Narayanan J, et al. Leader mindfulness and employee performance: a sequential mediation model of LMX quality, interpersonal justice, and employee stress. Journal of Business Ethics 2018;84:1-19.

26 Leonard HS, Lewis R, Freedman AM. The Wiley-Blackwell Handbook of the psychology of leadership, change and organizational development. Wiley Online Library, 2013.

27 Sauer S, Kohls N. Mindfulness in leadership: does being mindful enhance leaders' business success? Springer: Culture and neural frames of cognition and communication, 2011: 287-307.
28 Good DJ, Lyddy CJ, Glomb TM, et al. Contemplating mindfulness at work: an integrative review. Journal of management 2016;42:114-42.

29 Beach MC, Roter D, Korthuis PT, et al. A multicenter study of physician mindfulness and health care quality. Ann Fam Med 2013;11:421-8.

30 Beckman HB, Wendland M, Mooney C, et al. The impact of a program in mindful communication on primary care physicians. Acad Med 2012;87:815-9.

31 Boyatzis RE, Boyatzis R, McKee A. Resonant leadership: Renewing yourself and connecting with others through mindfulness, hope, and compassion. Harvard Business Press, 2005.

32 Morgan P, Simpson J, Smith A. Health care workers' experiences of mindfulness training: a qualitative review. Mindfulness 2015;6:744-58.

33 Raab K, Mindfulness RK. Mindfulness, self-compassion, and empathy among health care professionals: a review of the literature. $J$ Health Care Chaplain 2014;20:95-108.

34 Pinck AS, Sonnentag S. Leader mindfulness and employee wellbeing: the mediating role of transformational leadership. Mindfulness 2018;9:884-96.

35 Furtner MR, Tutzer L, Sachse P. The mindful self-leader: investigating the relationships between self-leadership and mindfulness. Soc Behav Pers 2018;46:353-60.

36 Kersemaekers WM, Vreeling K, Verweij $\mathrm{H}$. Effectiveness and feasibility of a mindful leadership course for medical specialists: a pilot study.

37 Tong A, Sainsbury P, Craig J. Consolidated criteria for reporting qualitative research (COREQ): a 32-item checklist for interviews and focus groups. Int J Qual Health Care 2007;19:349-57.

38 O'Brien BC, Harris IB, Beckman TJ, et al. Standards for reporting qualitative research: a synthesis of recommendations. Acad Med 2014;89:1245-51.

39 Germer $\mathrm{C}$. The mindful path to self-compassion: freeing yourself from destructive thoughts and emotions. Guilford Press, 2009.

40 Beck JS. Cognitive behavior therapy: basics and beyond. Guilford press, 2011.

41 Covey SR. The 7 habits of highly effective people: powerful lessons in personal change. Simon and Schuster, 2004

42 Hersey P, Blanchard KH, Johnson DE. Management of organizational behavior: Prentice Hall upper saddle river, NJ 2007.

43 Scharmer CO. Theory U: learning from the future as it emerges. Berrett-Koehler Publishers, 2009

44 Friese S. Qualitative data analysis with atlas. Ti. SAGE Publications Limited, 2019.

45 Glaser BG, Strauss AL. Discovery of grounded theory: strategies for qualitative research. Routledge, 2017.

46 Sarantakos S. Social research: Macmillan international higher education 2012.

47 Lampard R, Pole C. Practical social investigation: qualitative and quantitative methods in social research. Routledge, 2015.

48 Boeije H. Analysis in qualitative research. Sage publications, 2009.

49 Lyddy CJ, Good DJ. Being while doing: an inductive model of mindfulness at work. Front Psychol 2017;7:2060.

50 Irving JA, Park-Saltzman J, Fitzpatrick M, et al. Experiences of health care professionals enrolled in mindfulness-based medical practice: a grounded theory model. Mindfulness 2014;5:60-71.

51 Rupprecht S, Falke P, Kohls N, et al. Mindful leader development: how leaders experience the effects of mindfulness training on leader capabilities. Front Psychol 2019;10:1081.

52 Carson JW, Carson KM, Gil KM, et al. Mindfulness-based relationship enhancement. Behav Ther 2004;35:471-94.

53 de Vibe M, Solhaug I, Tyssen R, et al. Does personality moderate the effects of mindfulness training for medical and psychology students? Mindfulness 2015:6:281-9.

54 Avolio BJ, Gardner WL. Authentic leadership development: getting to the root of positive forms of leadership. Leadersh $Q$ 2005:16:315-38.

55 van Dierendonck D. Servant leadership: a review and synthesis. $J$ Manage 2011;37:1228-61. 